\title{
Co-culture of neural and smooth muscle cell lines: A model for the peripheral autonomic nervous system
}

\author{
Yasuhisa Endo ${ }^{1}$, Tatsuya Maruyama ${ }^{1}$ and Yasuharu Sasaki ${ }^{2}$ \\ ${ }^{1}$ Department of Applied Biology, Kyoto Institute of Technology, Sakyo, Kyoto 606, and ${ }^{2}$ Biochemical Research Laboratory, Life Sci- \\ ence Center, Asahi Chemical Industry Co., Ltd., Asahimachi, Nobeoka, Miyazaki 882, Japan
}

\begin{abstract}
PC12 cells and smooth muscle cell line (SM-3) were co-cultured to prepare a model of a peripheral autonomic nerve in contact with its target cells. PC12 cells differentiated into a multipolar neuronal type by nerve growth factor. SM-3 cell line derived from the rabbit aorta differentiated into smooth muscle-like cells under nutritional deficiency. Both cell types were easily distinguished by their cell shapes and further by immunohistochemistry using an antibody against neurofilament protein. Neurites of PC12 cells were often in contact with SM-3 cells. Under an electron microscope, large varicose fibers containing numerous large cored vesicles were found in close vicinity of SM-3 cells. Sometimes a membrane specialization was seen in both cell boundaries, indicative of synapse formation. This model seems useful for studying the relations between the peripheral autonomic nerve and the smooth muscle cells.
\end{abstract}

The terminal portions of the peripheral autonomic nerves generally show no clear synaptic contact with their target cells including smooth muscle cells, unlike in the case of neuromuscular junctions of motor endplates. Our previous scanning electron microscope study in the small intestine of the guinea pig showed that the terminal portions of the enteric neurons comprise a continuous network consisting of unmyelinated nerve fascicles (2). We further demonstrated by transmission electron microscopy non-synaptical release of neurotransmitters in the rat small intestine, using stimulation of high $\mathrm{K}^{+}$and $\mathrm{Ca}^{2+}$ and fixation with the tannic acid-osmium method (1). However, the relationship between the three-dimensional structures of the autonomic nerves, and the mechanism of innervation of their target tissues are not clear at present.

The aim of this study is to prepare a model of a peripheral autonomic nerve in contact with its target. As the neuronal element, PC12 cell line (PC12h, courtesy of Professor H. Hatanaka of Osaka University) was chosen; this cell line was derived from an adrenal tumor and differentiates into an aminergic, sympathetic neuronal type when stimulated by nerve growth factor. As a target cell, we used a new smooth muscle cell line (SM-3) established from the rabbit aorta (5). This cell line differentiates into smooth muscle-like cells, i.e. elongated, flattened cells, under nutritional deficiency (5). Our preliminary immunohistochemical investigation also showed that the differentiated SM-3 cells contained immunoreactivities for actin, slow myosin, vimentin and tubuin (unpublished data).

Both cell lines were subcultured with the Dulbecco's modified Eagle medium supplemented with $10 \%(\mathrm{v} / \mathrm{v})$ fetal bovine serum. For the experiments of co-culture, both cell lines were inoculated at a density of $10^{4}$ cells $/ \mathrm{cm}^{2}$ each in collagen-coated $35 \mathrm{~mm}$ dishes, and incubated with the medium consisting only of 0.5 or $1.0 \%$ serum. Nerve growth factor $(2.5 \mathrm{~S}$, Biomedical Technologies, MA, U.S.A.) was added every day to a concentration of $50 \mathrm{ng} / \mathrm{ml}$. For electron microscopy, cells were fixed with $2.5 \%$ glutaraldehyde and $1 \% \mathrm{OsO}_{4}$, dehydrated in an ethanol series, and embedded in Epon 812. Thin sections were stained with uranyl acetate and 


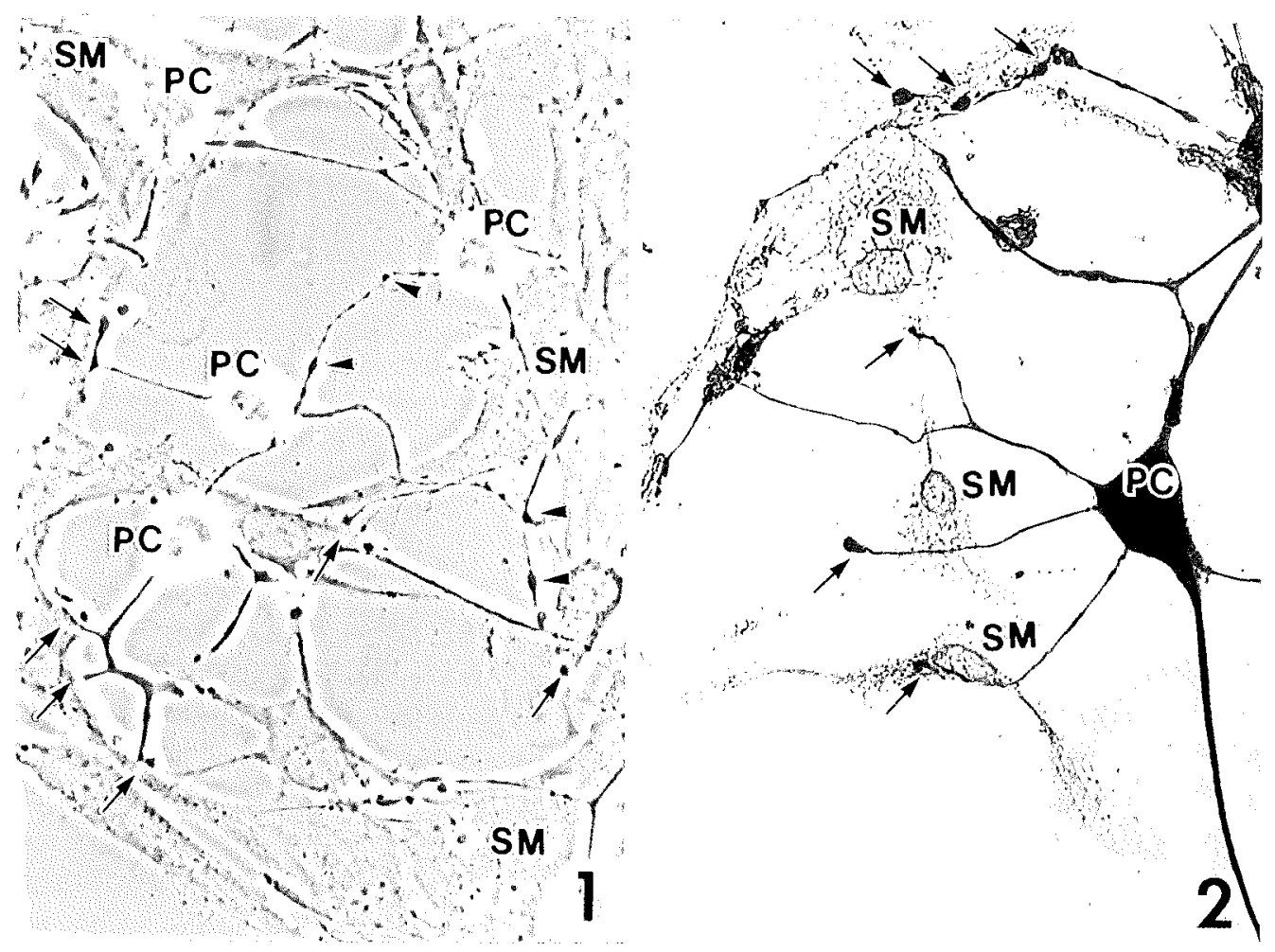

Fig. 1 Phase contrast micrograph showing a co-culture of PC12 and smooth muscle cells. PC12 cells (PC) are differentiated into a multipolar neuronal type showing several varicosities (arrowheads). SM-3 cells (SM) are conspicuously flattened, large cells. Specific contacts between both cell types are seen (arrows). $\times 250$

Fig. 2 Immunohistochemical demonstration of $150 \mathrm{~K}$ neurofilament protein in PC12 cells differentiated by nerve growth factor. Slender, varicose fibers of PC12 cells are immunopositive. Specific contacts (arrows) are found between PC12 and SM-3 cells. The immunostaining was done with the avidin-biotin complex system (vectastain). $\times 400$

lead citrate and examined with a JEM-100C electron microscope at $80 \mathrm{kV}$.

Three to five days after co-culture, PC12 cells extended several, long and thin neurites with large varicosities (Fig. 1, arrowheads), whereas SM-3 cells became to be extensively flattened. Although both cell types were easily distinguishable by their size and shape, further confirmation was made by immunohistochemistry using an antibody against neurofilament protein $(150 \mathrm{~K}$, Amersham), which was expressed only in PC12 cells (Fig. 2).

The varicosities of the neurites of $\mathrm{PC} 12$ cells were often recognized by phase contrast microscopy to be in contact with SM-3 cells (Fig. 1, arrows). This relation could be demonstrated more clearly by light microscope observation of the preparations stained with the neurofilament protein antibody (Fig. 2, arrows). The transmission elec- tron microscope observation confirmed large varicose fibers with numerous large cored vesicles closely contacting SM-3 cells (Fig. 3). Sometimes membrane specializations such as membrane thickening and sublemmal condensation of the cytoplasm were seen at both cell boundaries, indicative of synapse formation (Fig. 4, arrows). A specific contact between two neurites of $\mathrm{PC}-12$ cells was also found (Fig. 5). Our preliminary observations after microinjection of Luiffer yellow indicate that gap junctions are formed only between SM-3 cells, but not between PC12 cells, nor between PC12 and SM-3 cells (data not shown).

These observations suggest that the synaptic contact is formed in vitro between PC12 and SM-3 cells, although the electrophysiological demonstration is eventually required. At present, we cannot explain the discrepancy between the present study 


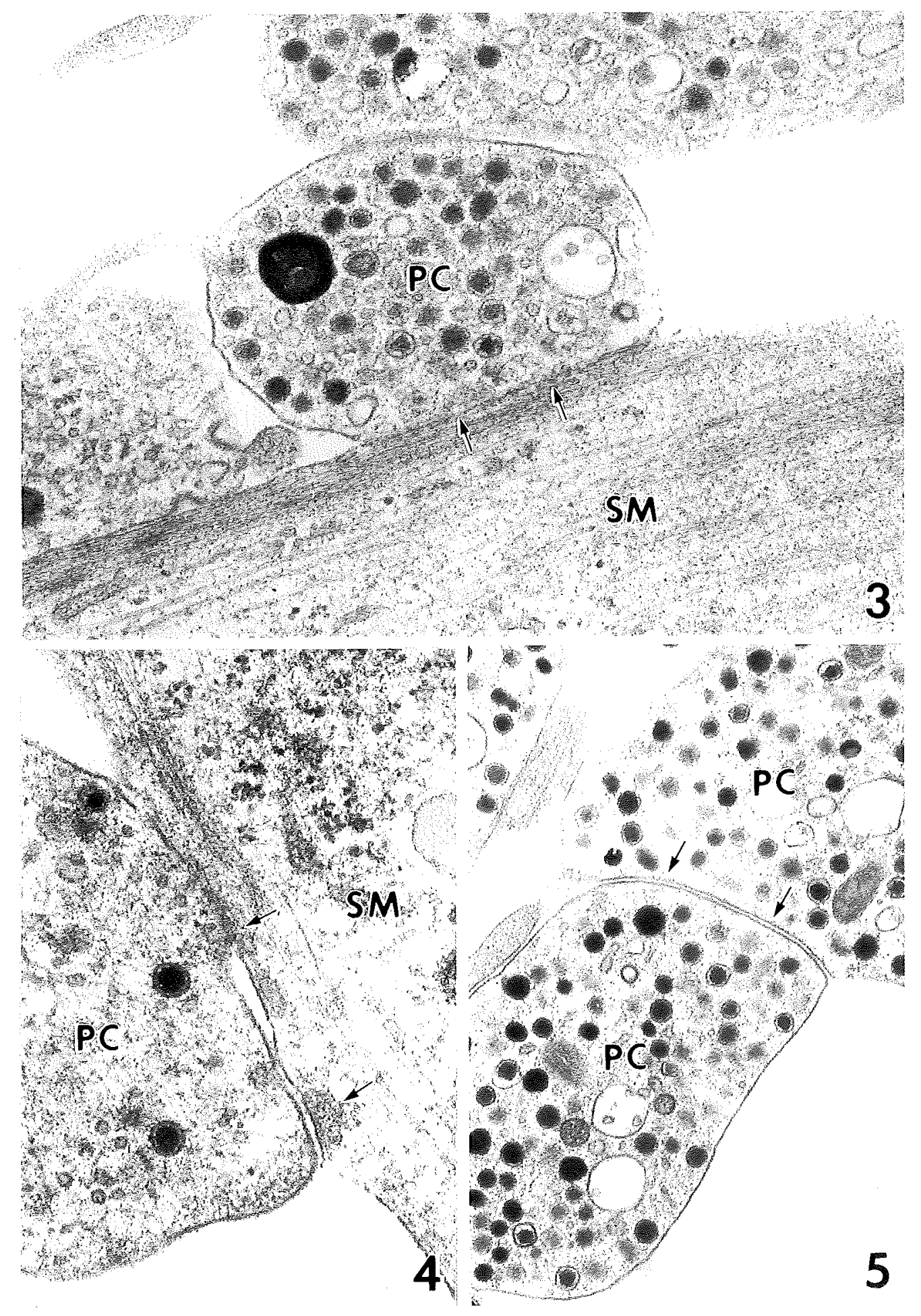

Fig. 3-5 Electron micrographs showing specific contacts (arrows) between a varicose fiber of PC12 cell (PC) and a smooth muscle cell (SM) (Figs. 3 and 4) and between PC12 cells (Fig. 5). Large terminals of PC12 neurites contain numerous large cored vesicles. The cell membrane exhibits sometimes specialized structures, including membrane thickening and condensation of the cytoplasm (Fig. 4, arrows). Fig. 3, ×35,000; Fig. 4, ×46,000; Fig. 5, ×28,000 
and our previous in vivo studies, where no synaptic innervation to smooth muscle cells was observed $(1,2)$. It is worthy of note that the present culture system does not contain glial cell elements. These are presumed to play essential roles in the formation of the terminal networks of the autonomic nerves in vivo $(3,4)$.

The present culture system seems to be a useful model for studying the cytological, physiological, and molecular basis of the autonomic innervation mechanism.

Received 8 February 1991; and accepted 19 March 1991

\section{REFERENCES}

1. ENDO Y. (1988) Non-synaptic release of transmitter-contain- ing vesicles from the enteric neurons of the rat small intestine. Zool. Sci. 5, 965-971

2. Endo Y. and KobaYashi S. (1987) A scanning electron microscope study on the autonomic groundplexus in the lamina propria mucosae of the guinea-pig small intestine. Arch. Histol. Japon. 50, 243-250

3. Kobayashi S., Suzuki M., Endo T., Tsuji S. and Daniel E. E. (1986) Framework of the enteric nerve plexuses: An immunocytochemical study in the guinea pig jejunum using an antiserum to S-100 protein. Arch. Histol. Japon. 49, $159-188$

4. Kobayashi S., SuZuki M. and Nishisaka T. (1989) Immunohistochemical studies on the regenerative features of nerve plexuses severed by spot irradiation with an argon laser beam in the guinea-pig small intestine. Biomedical Res. 10, Suppl. 3, 467-489

5. SASAKI Y., UCHIDA T. and SASAKI Y. (1989) A variant derived from rabbit aortic smooth muscle: Phenotype modulation and restoration of smooth muscle characteristics in cells in culture. J. Biochem. 106, 1009-1018 